\title{
Research into the Relationship between Ego States and Neuroticism among Indian Males and Females
}

\section{(C) 2019 Vijay Gopal Sreenivasan \& C. Suriyaprakash}

\begin{abstract}
Results are shown of a research project exploring the relationship between the transactional analysis concepts of ego states and Neuroticism in the Big Five Factor model of personality, A sample of 192 Indian adults (37\% male, $63 \%$ female) were administered the Ego State Questionnaire-Revised (ESQ-R) and the Big Five Inventory (BFI). Pearson Product-Moment Correlation indicated a small but positive correlation between Neuroticism and the ego states of Critical Parent and Adapted Child, and a small negative correlation between Neuroticism and Nurturing Parent, Adult and Free Child. (All correlations significant at 0.05 level using a twotailed test.) There were differences between males and females and between different age groups. Though there are limitations to this research, the findings are in line with TA theory and may have implications for how TA therapy is applied.
\end{abstract}

\section{Key words}

Big Five, ego states, Neuroticism, Transactional Analysis (TA), Personality

\section{Definitions and Key Terms \\ Ego states}

Transactional analysis (TA) conceptualises the personality of an individual as a three-part model of ego states, which Berne (1972) defined as "coherent systems of thought and feeling, manifested by corresponding patterns of behaviour" (p. 11). These are set apart from each other in three distinct ways which Berne (1961) called "exteropsyche (e.g., identificatory), neopsyche (e.g. data processing) and archaeopsyche (e.g. regressive) or colloquially as Parent, Adult and Child" (p. 3).

As explained by Stewart and Joines (1987), the above three-part ego state model is called the structural model of TA, which "we use when we want to examine the specific content of the ego states. It tells us what is there in each ego state. When we wish to study ego states in terms of how we use them, then we use a more detailed model of ego states called the functional model" (p. 21). The functional model divides the Parent and Child ego states into Critical Parent (CP) and Nurturing Parent (NP), and Adapted Child (AC) and Free Child (FC). These, with Adult (A), constitute the five-part functional model of ego states.

Given that each ego state has a positive and negative aspect to its functioning, (Kahler, 1977) it is helpful to think of each ego state as having a positive/ effective mode of operation and a negative/ ineffective mode of operation. This has been conceptualised by Susannah Temple (Temple, 2015) though her Temple Index of Functional Fluency (TIFF), the key concepts of which are:

- In the positive mode, CP is labelled Structuring and shows behaviour such as being inspiring, well-organised and firm. CP's negative mode is called Dominating and is characterised by being bossy, fault-finding and punitive.

- Similarly positive NP is called Nurturing and acts with compassion, understanding and acceptance. Negative mode of NP is called Marshmallowing and can be discerned when you see overindulgence, inconsistence and smothering.

- Positive AC shows friendly, considerate and assertive behaviour and is labelled Cooperative mode. Negative AC shows anxious, rebellious or submissive behaviour and is labelled Compliant/ Resistant mode.

- TIFF refers to positive FC as Spontaneous (creative, zestful, expressive) and negative FC as Immature (egocentric, selfish, reckless).

- Only the Adult ego state is not divided into negative or positive modes of operating. It is characterised as operating in an Accounting mode which is rational, evaluative, alert and aware. 
According to Temple, all human behaviour will fall into one of the four positive modes $(+\mathrm{NP},+\mathrm{CP},+\mathrm{AC}$ $\&+\mathrm{FC})$ when the Adult is in the Accounting mode; and into one of the negative modes (-NP, -CP, -AC $\&-F C$ ) when the Adult is not in the Accounting mode.

\section{Personality and Five Factor Theory}

The study of personality has had many approaches (Schultz and Schultz, 2013). This research relies on the trait approach to personality - a school of thought pioneered by Gordon Allport, Raymond Cattell and Hans Eysenck. McCrae and Costa (2008) define traits as "more-or-less consistent and recurrent patterns of acting and reacting that simultaneously characterise individuals and differentiates them from others, and they allow the discovery of empirical generalisation about how others with similar traits are likely to act and react" (p. 160).

Nettle (2007) points out that all of us have traits, although we differ in the degree to which each trait is manifested or expressed in our personalities. As he evocatively puts it "traits are continuous, like height is, rather than discrete, like being an apple versus pear" (p. 20).

John, Naumann and Soto (2008) show that the dominant model of personality is the Five-Factor
Theory (FFT) personality system developed by Robert McCrae and Paul Costa. They provide a definition and explication of the Big Five domains as depicted in Table 1, and state "rather than replacing previous systems, the Big Five taxonomy serves as an integrative function because it can represent the various and diverse systems of personality descriptions in a common framework" (p. 116). Nettle (2007) also states that the "five-factor model looks to be the most comprehensive, reliable and useful framework for discussing human personality that we have ever had" (p. 9).

\section{Neuroticism}

Nolen-Hoeksema, Fredrickson, Loftus and Lutz (2014) define Neuroticism as "a dimension of emotionality, with moody, anxious, temperamental and maladjusted individuals at the neurotic or unstable end, and calm, well-adjusted individuals at the other" (p. 437). It is one of the five factors in the FFT and comprises six domains: Anxiety, Angry Hostility, Depression, Self-consciousness, Impulsiveness and Vulnerability (Weiner \& Greene, 2008, p. 316). Neuroticism, or traits similar to it, have been consistently identified historically by researchers such as Robert Cattell and Hans Eysenck (Schultz \& Schultz, 2013, p. 217-228).

\begin{tabular}{|c|c|c|}
\hline Factor & Verbal Labels & Conceptual definition \\
\hline E (Factor I) & $\begin{array}{l}\text { Extraversion. } \\
\text { Energy, } \\
\text { Enthusiasm }\end{array}$ & $\begin{array}{l}\text { Implies an energetic approach toward the social and material world and } \\
\text { includes traits such as sociability, activity, assertiveness and positive } \\
\text { emotionality }\end{array}$ \\
\hline A (Factor II) & $\begin{array}{l}\text { Agreeableness. } \\
\text { Altruism, } \\
\text { Affection }\end{array}$ & $\begin{array}{l}\text { Contrasts a prosocial and communal orientation toward others with } \\
\text { antagonism, and includes traits such as tender-mindedness, trust and } \\
\text { modesty }\end{array}$ \\
\hline C (Factor III) & $\begin{array}{l}\text { Conscientiousness. } \\
\text { Constraint, } \\
\text { Control of impulse }\end{array}$ & $\begin{array}{l}\text { Describes socially prescribed impulse-control that facilitates task and } \\
\text { goal-directed behaviour, such as thinking before acting, delaying } \\
\text { gratification, following norms and rules, and planning, organising and } \\
\text { prioritising tasks }\end{array}$ \\
\hline N (Factor IV) & $\begin{array}{l}\text { Neuroticism. } \\
\text { Negative emotionality } \\
\text { Nervousness }\end{array}$ & $\begin{array}{l}\text { Contrasts emotional stability and even-temperedness with negative } \\
\text { emotionality such as feeling anxious, nervous, sad and tense. }\end{array}$ \\
\hline O (Factor V) & $\begin{array}{l}\text { Openness to experience. } \\
\text { Originality, } \\
\text { Open-mindedness }\end{array}$ & $\begin{array}{l}\text { Describes the breadth, depth, originality and complexity of an } \\
\text { individual's mental and experiential life. }\end{array}$ \\
\hline
\end{tabular}

Note. The FFT is also informally called the Big Five factor model of personality.

Table 1: Big Five factor model of personality (John et al, 2008. p. 120) 


\section{Review of literature}

\section{Research on Ego States and Big Five Factor Model}

A search for similar research on the relationship between ego states and the Big Five Factor model yielded only one pilot, exploratory research (Ciucur, 2013). This study covered 42 female school psychologists and counsellors in Timisoara, Romania. It used the DECAS Big Five Inventory (Sava, 2013) and the Ego States Questionnaire (correct title Personal Styles Questionnaire, Hay, 1992) to collect data and the Bravais-Pearson " $r$ " correlation test to identify potential relationships. The key finding of this study that is relevant to us is "a significant negative correlation between Adapted Child and Emotional Stability" Ciucur (2013, p. 583). No other significant correlation was found between Emotional Stability (i.e. the term DECAS inventory uses as the opposite of Neuroticism) and other ego states. It is interesting to note "that Critical Parent was seen as negatively correlating with Agreeableness and not with Emotional Stability" (p. 584).

Ciucur (2013) has also listed the limitations of his research; a small sample size and exclusively female. Also, his research did not discriminate between positive and negative aspects of the ego states.

Research on relationships between ego states, locus of control and dogmatism

Loffredo (1998) studied the relationship between ego states and personality constructs such as locus of control and dogmatism. Locus of control was defined as "the perception of the extent to which positive and/or negative events are considered a consequence of one's own actions (internal locus of control) or not (external locus of control)" (p. 171). Dogmatism was defined as "the relatively closed cognitive organisation of beliefs about reality, focussed around a central set of beliefs about absolute authority which, in turn, provides a framework for patterns of intolerance and qualified tolerance towards others" (p. 171).

Using Pearson $r$ correlation, Loffredo's research showed eleven significant correlations. The relevant ones are summarised below:

1. There was a significant negative correlation between the Adult ego state and external locus of control. This is consistent with TA ego state theory which states that those "with activated Adult ego states show good problem solving - a quality associated with those with high internal locus of control" (p. 172).

2. There was a significant positive correlation between the Adapted Child (AC) ego state scores and the external locus of control scores. Again, this finding was consistent with ego state theory as people with an activated AC "are frequently externally oriented... behave in ways that are considered best for getting along with others instead of autonomously and would therefore be expected to demonstrate a marked propensity to over-adapt to external locus of control" (p. 172).

3. There was a significant positive correlation between the Adapted Child (AC) and dogmatism again consistent with the theory of TA. This is because the AC "develops a response to significant, more powerful others...in whom the dogmatic individual seeks safety" (pp 172-173).

Research on ego states and application to drug abuse clients

Doelker and Griffiths (1984) developed an Ego State Energy Inventory by adapting Heyer's (1979) ego state profile. They developed a 75 -item questionnaire, with 15 statements for each of the five ego states. They administered the instrument to 57 social work undergraduate students and later to a group of 72 adults undergoing therapy in a residential drug abuse treatment program. They found that the social work students exhibited elevated scores on NP, FC and Adult ego states as compared to the $\mathrm{CP}$ and $\mathrm{AC}$ ego states. Among the drug abuse clients, the CP and $A C$ ego states were less represented than the other ego states (p. 52).

Research on ego states and psychopathology Thorne and Faro (1980) developed the Ego State Scale to measure ego states and explore their relationship with depression, schizophrenia, hysteria, etc. They studied eight ego states (+NP, $\mathrm{NP},+\mathrm{CP},-\mathrm{CP}, \mathrm{A},+\mathrm{AC},-\mathrm{AC}$ and FC), and developed an instrument with a total of 30 adjectives for each ego state. They analysed the relationship between individual ego state scales and MMPI (not referenced by Thorne \& Faro but presumably Hathaway and McKinley, 1940) indices using a Pearson correlation coefficient. It was found that "as the number of extreme MMPI scale scores increased, indicating increased pathology, scores on -AC and -NP increased while scores on +FC and A decreased" ( $p$. 51).

Essentially, they found "that FC, A, +NP and $+\mathrm{CP}$ were shown to be negatively correlated with pathology as measured on the MMPI, while -AC, -NP and -CP were positively correlated with pathology" (p. 51). Overall, the authors state that "high -AC scores were the best single indicator of pathology" (p. 51), and that " $+A C$ is not necessarily indicative of psychological health" (p. 51). 
Another interesting finding by the researchers was "that +NP was not found to be as highly negatively correlated with pathology as +CP" (p. 51). The authors say "while this would indicate that while both ego states are inversely related to pathology, the protective, limit-setting role of $+\mathrm{CP}$ is more central to psychological health than is the warm, supportive, permission-giving role of +NP" (p. 51). Equally interesting is that "-NP was shown to be more highly correlated with pathology than -CP...it is not unreasonable to assume that the overt expression of feelings consistent with -CP is less personally destructive than is the internalisation of feelings that occurs in -NP" (p. 52).

The overall conclusion by the authors was "that a significant relationship exists between ego state patterns and psychopathology" (p. 52).

\section{Research on ego states and application to psychiatry}

Robert Heyer (1979) developed an instrument called the Heyer Ego State Profile (ESP) and applied it to recovering alcoholics and prison inmates. The ESP is a fifty-item questionnaire that assessed individuals on the five ego states.

His research conclusions showed that the "CP correlates positively with dogmatism, negatively with acceptance of others and insignificantly with selfesteem" (p. 11). "The NP showed a positive correlation with both self-esteem and acceptance of others, with an insignificant correlation with dogmatism" (p.12). "The Adult ego state was most highly correlated with self-esteem, moderately associated with acceptance of others. There is no consistent relationship between the Adult ego state and dogmatism" (p. 12). The "FC was positively related to self-esteem and to acceptance of others, and is negatively correlated with dogmatism, and the AC was negatively correlated with self-esteem and with acceptance of others" (p. 12). These findings were consistent with what TA theory predicts and Heyer concluded that "the ESP lends empirical support to ego state concepts which TA theory developed from clinical observation" (p. 12).

$\mathrm{He}$ also found gender differences with the ESP noting that "Critical Parent $(\mathrm{CP})$ is consistently higher among men than women and it tends to decrease with age. Nurturing Parent (NP) is significantly higher among women than among men and tends to increase with age" (p. 12).

His study of alcoholics showed that they had distinctly elevated AC ego states and markedly lower than average Adult when compared to general population norms (p.15). These findings were in line with what TA theory posits. However, there were deviations as well - for example, his study did not support the hypothesis that alcoholics have lower than average $\mathrm{FC}$ (p. 15).

\section{Rationale of the study}

Loffredo (1998) states that "few attempts have been made to integrate different measures of psychological constructs/traits with different theories of personality" (p. 171). The same picture is echoed by Ciucur (2013) when he reports that "no previous empirical researches approaching the relations between Transactional Analysis Ego States and the Big Five Personality Factors in the existing research literature were found" (p. 581). Therefore there is a need to bring TA up-to-date by relating classical theoretical concepts of TA to current developments in other branches of psychology. This research therefore assumes significance in the direction of bridging this gap.

In India, the World Health Organisation ([WHO], 2019) estimates that "the burden of mental health problems is of the tune of 2,443 Disability Adjusted Life Years (DALY) per 100,000 population. It is estimated that, in India, the economic loss, due to mental health conditions, between 2012 and 2030, is 1.03 trillions of 2010 dollars" (Mental health in India, para 8). Nettle (2007) states "Neuroticism is not just a risk factor of depression. It is so closely associated with it that it is hard to see them as completely distinct" (p. 114). He further states that "anxiety disorders, phobias, eating disorders, post-traumatic stress disorders, obsessive compulsive disorders all these are characterised by heightened Neuroticism" (p. 117). He also describes the deleterious effect of heightened Neuroticism such as impaired immune systems, insomnia, schizophrenia, headaches, less satisfactory marriages and less satisfaction at work. Interestingly, he has also pointed out some of the potential positive spinoffs from managing Neuroticism healthily - such as using Neuroticism's capacity for sensitive insights into the human condition, realistic appraisal of danger, protective effects of vigilance and the opportunity for striving for achievement to mitigate suffering.

If TA therapists can gain a deeper insight into Neuroticism, through the research reported here, and thereby help clients buttress the strengths of Neuroticism and moderate its negative effects, this research will have contributed in its small way towards the cause of improving mental health.

Finally, the significance of this research stems from the possibility of extending this research to include other factors of personality. There were at least four other personality factors that could have been studied further: Openness to Experience, Conscientiousness, Extraversion and Agreeableness. A comprehensive understanding of the relationship 
between TA ego states and all five factors of the Big Five can significantly enhance the state of TA theory and practices. It can equip TA practitioners with the rationale for leveraging ego state theory to enhance or moderate the effects of specific personality traits.

\section{Research methodology}

The study commenced in February 2019 and continued till April 2019. It was conducted primarily out of Mumbai but the participants in the study were drawn from across India.

\section{Research objectives and hypotheses}

To explore the relationship between the ego states of TA and Neuroticism of the Big Five model using correlational analysis, and draw inferences that may impact TA theory or practice.

This research tested five null hypotheses: that there is no correlation between each ego state i.e. NP, CP, A, AC, FC, and Neuroticism

\section{Variables}

The two sets of variables that were analysed for correlation were Neuroticism and the five ego states of TA: NP, CP, A, AC and FC.

For the purposes of the study, Neuroticism means the tendency to experience dysphoric affect such as sadness, hopelessness and guilt (McCrae \& Costa, 2008). The following conceptual definitions of the five ego states are taken from Williams and Williams (1980, p. 120):

- $\quad$ CP: designates a set of feelings, attitudes and behaviour patterns which resembles those of a parental figure which criticises, finds fault, reflects the rules of society, and the values of the individual.

- NP: is a set of feelings, attitudes and behaviour patterns that represent a parental figure which nurtures and promotes growth.

- A: represents feelings, attitudes and behaviour patterns which are adapted to current reality, used for logical reasoning and precise predictions.

- FC: embraces feelings, attitudes and behaviour patterns which are relics of an individual's own childhood and characterised by fun, selfindulgence and natural, spontaneous feelings.

- $\quad$ AC: a set of feelings, attitudes and behaviour patterns manifested by compromising and conforming behaviours resulting from the domination of parental influence.

As described by John et al (2008), Neuroticism means the average score (after the raw score is ipsatized) of the eight items constituting the Neuroticism scale in the Big Five Inventory [BFI].
As described by Loffredo and Harrington (2012), the five ego states each mean the total score of the eight items constituting that particular ego state as defined in the Ego State Questionnaire- Revised [ESQ-R].

Instruments

The two instruments used were ESQ-R by Loffredo and Harrington (2012, pp. 94 - 96) and BFI by John, Naumann, Laura, Soto, Christopher (2008, pp. 157 - 158). MS-Excel and Google Forms were also used.

\section{Study design}

This research design was a descriptive research (Kothari \& Garg 2014)). It did not attempt to determine causality between the independent and dependent variables, nor did it conduct an experiment between a control and experimental group. Rather, this research built on existing literature and used psychometric instruments to describe the existence of a relationship between ego states and Neuroticism. This will hopefully lay the basis for further - more precise - investigation, such as determining causality between shifts in ego states and personality, or the effect of TA therapy on personality.

\section{Sampling technique}

The respondents were selected through a process of convenience sampling and snowball sampling. They were contacted by email from a list of personal contacts of the primary author and by reaching out to members of the South Asian Association of Transactional Analysts (SAATA) headquartered out of Coimbatore, India. The respondents were also requested to forward the invitation to individuals they knew.

\section{Sampling criteria and selection}

The criteria for including subjects were that they should be:

1. Indian adults (male and female) in the agegroup of 25-58

2. Willing to voluntarily participate in the survey

3. Familiar with English as a language

Sample size

A total of 198 respondents took the survey. Five of these indicated a nationality other than Indian and hence were excluded. One respondent responded to all questions with a 'Neutral' rating and hence was also excluded. The final sample size was therefore $\mathrm{N}=192$. As we can see in Table 2, the proportion of females in the sample (63\%) was significantly more than the proportion of males in the sample (37\%). A majority of the sample were in the age group of 2540 years $(62 \%)$, which is not representative of the Indian population in general. Hence, we need to be careful in making generalisations from this research to the entire population. 


\begin{tabular}{|c|c|c|c|c|c|}
\hline Gender & Male & Female & Prefer Not to Say & Total & Percentage \\
\hline Below 25 years & 7 & 16 & 0 & 23 & $12 \%$ \\
\hline $25-40$ years & 48 & 71 & 0 & 119 & $62 \%$ \\
\hline 41-56 years & 14 & 29 & 0 & 43 & $22 \%$ \\
\hline$>56$ years & 2 & 4 & 0 & 6 & $3 \%$ \\
\hline Prefer Not to Say & 0 & 0 & 1 & 1 & $0 \%$ \\
\hline Total & 71 & 120 & 1 & 192 & $100 \%$ \\
\hline Percentage & $37 \%$ & $63 \%$ & $0 \%$ & $100 \%$ & \\
\hline
\end{tabular}

Note. All percentages rounded.

Table 2: Age and gender distribution in sample

Data collection tools for ego states

A literature review based on a list compiled by Akkoyun (2014) of 15 ego state research instruments led us to consider the Ego State Scale (Thorne and Faro, 1980), the Ego State Energy Inventory (Doelker and Griffiths, 1984), the Ego State Profile (Heyer, 1979) and the Ego State Questionnaire Revised [ESQ-R] (Loffredo, Harrington, Munoz \& Knowles, 2004). Except for the ESQ-R, the other instruments were outdated and their authors were not contactable for any updates made to their instrument. The ESQ-R questionnaire with scoring key (Loffredo and Harrington, 2012, pp. 94 - 96) was finally selected for this research because it is relatively recently developed and it has been rigorously tested.

Data collection tools for Big Five

John et al (2008) have extensively described the history, concepts and measurement of the Big Five personality factors and compared three tools for measurement:

1. The NEO FFI: Neuroticism Extraversion Open ness Five Factor Inventory developed by Robert McCrae and Paul Costa in 1992.

2. The TDA: Trait Descriptive Adjectives developed by L. R. Goldberg in 1992

3. The BFI: Big Five Inventory developed by Oliver John in 1991

After considering all factors such as statistical rigour, cost of purchasing the instruments, access to literature and ease of administration, it was decided to use the BFI for measuring Neuroticism in this research.
Data collection procedure

The ESQ-R and BFI were administered online through Google Forms. The survey was tested in late January 2019 through a pilot survey across 10 respondents. Feedback was incorporated into the revised survey which was launched in late February 2019. The survey was finally closed in late April 2019.

Once the raw data was collected, the BFI data was ipsatized using the approach mentioned by John et al (2008, p. 158) and then scored for Neuroticism by taking the mean score of the items measuring

Neuroticism. For the ESQ-R data, the total scores for each of the five ego states were calculated as per the items mapped to each of the ego states.

The mean and standard deviations for each individual's set of responses were calculated. The sample mean and the sample standard deviation were used to convert the individual scores of ego states and Neuroticism into standardised scores. This was done to enable correlation of data within the normal range of the bell curve, to not have outliers skew the analysis.

Following this, Pearson Product Moment Correlation was calculated between the standardised scores of the ego states of the ESQ-R with that of the Neuroticism score of the BFI. The correlation was tested for significance at a 0.05 level (2-tailed). Conclusions about the five null hypotheses were then drawn as shown in Table 3.

\section{Ethical considerations}

The following ethical considerations were followed during the conduct of this research: 


\begin{tabular}{|c|c|c|c|c|c|}
\hline & \multicolumn{5}{|c|}{ Ego states } \\
\hline Neuroticism & NP & CP & A & AC & FC \\
\hline Males (N=71) & -.514 & .622 & -.627 & .587 & -.386 \\
\hline $\begin{array}{c}\text { All Respondents } \\
\text { (N=192) }\end{array}$ & -.347 & .523 & -.622 & .638 & -.496 \\
\hline
\end{tabular}

Note. $\mathrm{p}<0.05$, two-tailed test. 'All Respondents' includes one participant who did not wish to identify his/her gender. (The significance testing for these correlations are shown in Tables 5-7 in Appendix A.)

Table 3: Correlations between ego states and Neuroticism (All respondents)

- Confidentiality: The survey did not ask for any information (such as name, email-id, phone number, IP-address) that would identify an individual respondent.

- Informed consent: The survey had a brief preamble that solicited participation, explained the rationale of the research (without naming the personality models being studied), assured confidentiality and offered the contact details of the author if respondents needed clarifications before they attempted the survey. All respondents were explicitly requested to confirm that their participation was voluntary and that they would provide their honest responses. In case respondents disagreed with any of these terms, they would automatically be prevented from participating in the survey.

\section{Results and Discussion}

Hypothesis testing

Each of the five null hypotheses was tested at 0.05 level of significance and the interpretation of each relationship is explained below.

\section{$\mathrm{H}_{0}$ : There is no correlation between Nurturing Parent and Neuroticism}

There is a weak negative relationship between NP and Neuroticism $(r(190)=-.347, p=.00)$. Hence, the null hypothesis is rejected. The scatterplot for this is shown in Figure 1. For females, the relationship between NP and Neuroticism is negligible and negative $(r(118)=-.249, p=.00)$ but for males there is a weak negative relationship $(r(69)=-.514, p=$ $.00)$. It can be inferred this difference between the genders indicates that within the Indian cultural context, where women are traditionally expected to frequently play nurturing roles, the NP ego state does not have a strong relationship when it comes to Neuroticism for females.

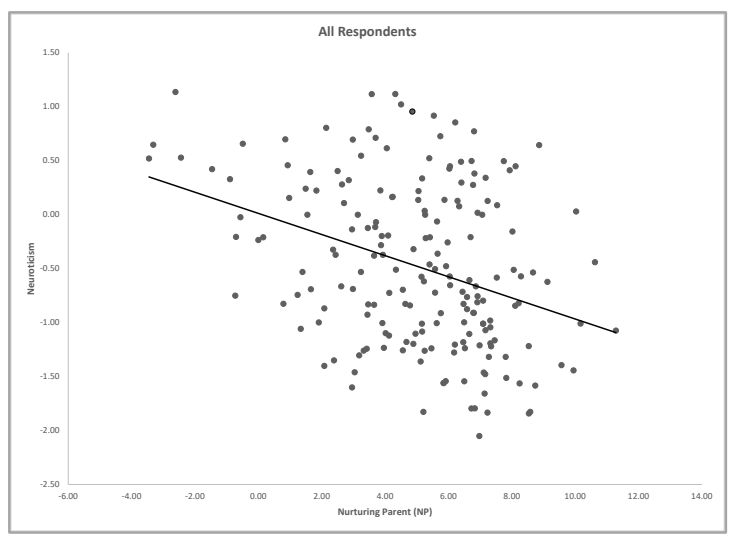

Figure 1. Weak negative $r$ between Nurturing Parent (NP) and Neuroticism.

\section{$H_{0}$ : There is no correlation between Critical Parent and Neuroticism}

There is a moderate, positive relationship between $\mathrm{CP}$ and Neuroticism $(r(190)=.523, p=.00)$. Hence, the null hypothesis is rejected. The scatterplot for this is shown in Figure 2. For females, there is a weak positive correlation $(r(118)=.463, p=.00)$ while for males it is a moderately positive correlation $(r(69)=$ $.622, p=.00$ ). It can be inferred that across genders, the CP has a positive correlation with Neuroticism.

\section{$\mathrm{H}_{\mathrm{o}}$ : There is no correlation between Adult and Neuroticism}

There is a moderately negative relationship between the Adult ego state and Neuroticism $(r(190)=-.622$, $p=.00$ ). Hence, the null hypothesis is rejected. The scatterplot for this is shown in Figure 3. This holds across genders - for males, $(r(69)=-.627, p=.00)$; for females, $(r(118)=-.625, p=.00)$. Among negative correlations, the relationship between the Adult ego state and Neuroticism is the strongest as compared to other ego states and Neuroticism. This is not surprising considering that every other ego 


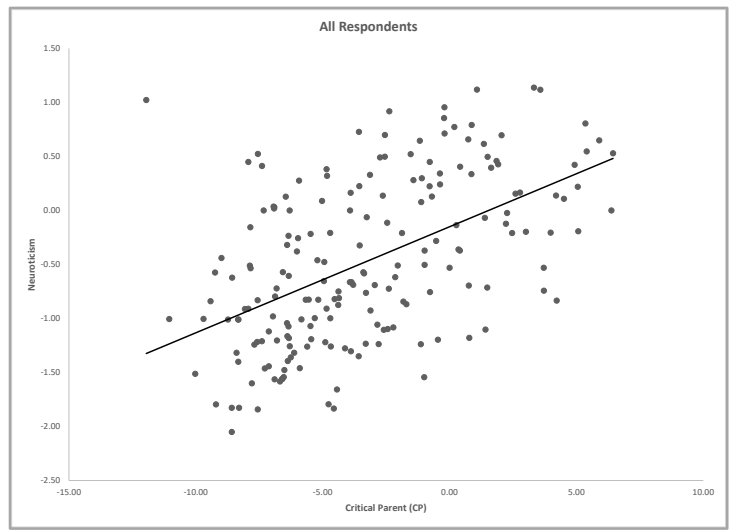

Figure 2. Moderately positive $r$ between Critical Parent (CP) and Neuroticism.

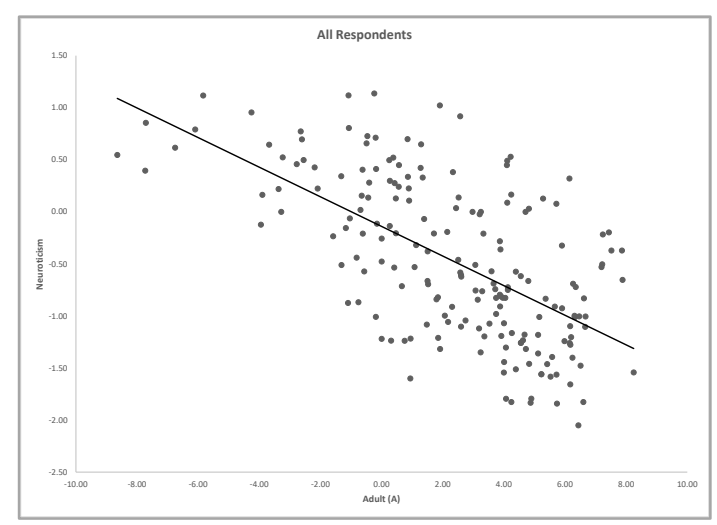

Figure 3. Moderately negative $r$ between Adult $(A)$ and Neuroticism.

state has its positive and negative modes of operation. The Adult alone does not have such dual modes of operation. Hence, it would be logical to surmise that the Adult ego state would have a stronger negative relationship than other ego states with Neuroticism.

\section{$\mathrm{H}_{\mathrm{o}}$ : There is no correlation between Adapted Child and Neuroticism}

There is a moderately positive relationship between $\mathrm{AC}$ and Neuroticism $(r(190)=.638, p=.00)$. Hence, the null hypothesis is rejected. The scatterplot for this is shown in Figure 4. Across genders too, there is a moderately positive relationship between $A C$ and Neuroticism: for males $(r(69)=.587, p=.00)$ and for females $(r(118)=.668, p=.00)$.

\section{$\mathrm{H}_{\mathrm{o}}$ : There is no correlation between Free Child and Neuroticism}

There is a weak negative relationship between FC and Neuroticism $(r(190)=-.466, p=.00)$. Hence, the null hypothesis is rejected. The scatterplot is shown in Figure 5. Across genders too, this weak negative correlation persists: for males, $(r(69)=-.386, p=.00)$ and for females $(r(118)=-.499, p=.00)$.

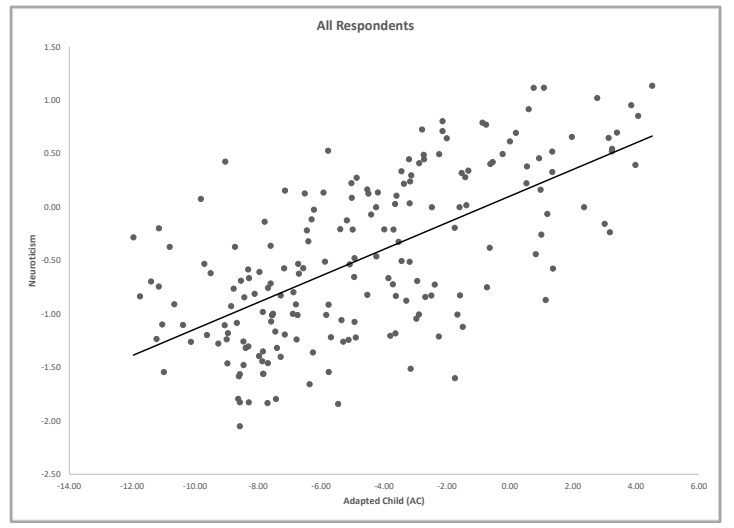

Figure 4. Moderately positive $r$ between Adapted Child (AC) and Neuroticism.

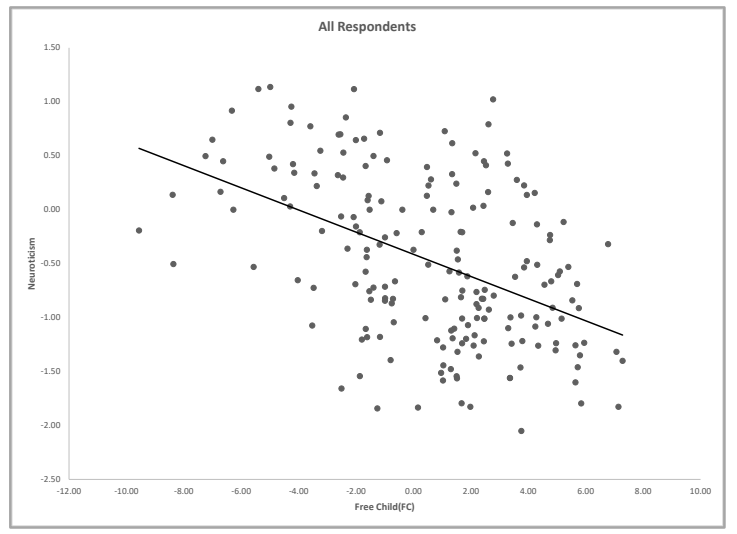

Figure 5. Weak negative $r$ between Free Child (FC) and Neuroticism.

\section{Age-related inferences}

The data was also tested for different age groups. The age groups of Below 25 years and Above 56 years were not considered as the number of data points were less than 30 . The results of the correlations between ego states and Neuroticism by the remaining two age groups (Between 25 and 40 years; and between 41 and 56 years) are summarised in Table 4. This analysis indicates that the direction of the correlations between Neuroticism and the ego states are the same as that of the correlational analysis seen at the aggregate level (Table 3). Further, it can be seen in Table 4 that the degree of correlation increases from the younger age group to the older age group with all ego states except FC.

\section{Conclusions}

From the observations, the following conclusions can be drawn:

1. At an aggregate level (Table 3 ), there is a positive correlation between Neuroticism with $\mathrm{AC}$ and $\mathrm{CP}$. There is a negative correlation 
between Neuroticism and FC, A and NP. This is consistent with TA theory - see Ciucur (2013), Loffredo (1998), Thorne and Faro (1980) and Robert Heyer (1979).

In the aggregate analysis (Table 3), the degree to which $\mathrm{CP}$ is correlated positively with Neuroticism $(r(190)=.523, p=.00)$ is stronger than the degree to which NP is correlated negatively with Neuroticism $(r(190)=-.347, p=$ .00 ). Similarly, the degree to which $A C$ is correlated positively with Neuroticism $(r(190)=$ $.638, p=.00)$ is stronger than the degree to which FC is correlated negatively with Neuroticism $(r(190)=-.466, p=.00)$. This trend holds true even when the data is analysed at the gender level or at different age groups. This makes for an unfortunate inference - namely that the strength of the deleterious relationships (positive correlations) between ego states with Neuroticism, are stronger than the strength of the benign relationships (negative correlations).

2. The potential implication for TA therapy is that strengthening the benign relationships will take more effort, compared to the effort that established the deleterious relationships in the first place.

3. Further, as seen in Table 3, among negatively correlated ego states, NP is most weakly correlated with Neuroticism for women $(r(118)=$ $-.249, p=.00)$ but for men it is stronger $(r(69)=$ $-.514, p=.00)$. Similarly, FC is most weakly correlated with Neuroticism for men $(r(69)=$ $.386, p=.00)$, but for women the relationship is stronger $(r(118)=-.499, p=.00)$. This indicates that therapy may need to be differentiated depending on gender.

4. When we see the trend in correlation between ego states and Neuroticism among different age groups (Table 4), then it indicates that proactive
TA interventions need to be designed for young people in order to pre-empt issues later in life.

5. None of the relationships (Table 3 and Table 4) were strongly negative or strongly positive, i.e. none of the correlations were greater than +/0.75 . One reason could be that the ESQ-R does not discriminate between the positive and negative modes of each ego state, and hence we cannot precisely discriminate the relationship between ego states with Neuroticism. Another potential reason could be the sample size and technique used. A much larger sample size and more rigorous techniques of sampling need to be used for arriving at a representative sample of the Indian population.

\section{Implications for therapy}

A correlational analysis cannot draw any conclusions about causality between ego states and Neuroticism. It is also a given that TA therapists can only work with the ego states of an individual and not directly on Neuroticism per se. Dusay (1972) proposed that the total psychic energy within an individual remains constant, and hence if one ego state is strengthened in intensity then another must correspondingly decrease in its intensity.

Keeping these aspects in mind, some inferences may be drawn to alleviate the ill-effects of Neuroticism:

- In general TA therapists may consider interventions that are aimed at increasing A, NP and FC of clients.

- When it comes to Indian women, TA therapists could focus on strengthening the $A$ and $F C$ in particular. For Indian men, TA therapists could consider strengthening $A$ and NP in particular.

- It would help to introduce young adults (collegelevel students) to therapeutic or educational

\begin{tabular}{|c|c|c|c|c|c|}
\hline \multirow{2}{*}{ Neuroticism } & \multicolumn{5}{|c|}{ Ego states } \\
\cline { 2 - 6 } & NP & CP & A & AC & FC \\
\hline $\begin{array}{c}\text { Age between 25 and 40 years; } \\
\mathbf{( N = 1 1 9 )}\end{array}$ & -.316 & .489 & -.591 & .607 & -.505 \\
\hline $\begin{array}{c}\text { Age between 41 and 56 years; } \\
(\mathbf{N = 4 3 )}\end{array}$ & -.388 & .519 & -.672 & .735 & -.382 \\
\hline
\end{tabular}

Note. $\mathrm{p}<.05$ levels, two-tailed test. (The significance testing for these correlations are presented in Tables 8-9 in Appendix A.)

Table 4: Correlations between ego states and Neuroticism (By age) 
interventions that strengthen $\mathrm{A}, \mathrm{NP}$ and $\mathrm{FC}$ to pre-empt the ill-effects of Neuroticism in later life. TA theory with its informal language, intuitive appeal and yet rigorous constructs can be an ideal vehicle to do so.

\section{Limitations of the study and suggestions for further work}

This study only measures the degree and direction of relationship between ego states and Neuroticism, and not causality. Experimental and control groups or longitudinal studies might help establish causality, and hence validate the impact of TA.

The ESQ-R does not differentiate between the positive and negative modes of the ego states; this may be why none of the correlations are strong. This points to a need for making a more nuanced instrument of ego states - one that differentiates between the positive and negative modes of ego states - to be made freely available for researchers.

Different models of ego states include an option for A to have negative modes (Schaefer, 1976; Hay, 1992) which might result in significantly different correlations.

This study has been based on models labelled functional ego states but which are in fact the descriptive model described by Berne, so the results refer to observable behaviours. In the case of Adult this may be significant because logical, problemsolving behaviour may not necessarily indicate that an individual is in the here-and-now in the same way that is implied by Berne's structural model and neopsyche.

The sample for this study has been restricted to adult Indian males and females. Hence, the findings cannot be generalised across cultures and other countries. Also, since the sample has been drawn from an English-speaking urban population, the findings cannot confidently be generalised to the non-English-speaking rural population of India. Future research studies will therefore need to cover a much wider sample of population, and for that the instruments would need to be translated.

The proportion of male respondents in the sample $(37 \%)$ is significantly less than the proportion of female respondents in the sample $(63 \%)$. This is not representative of the general Indian population, and hence findings based on gender should be further tested with more robust sampling procedures.

This research has focussed on one factor of the Big Five model - namely Neuroticism. The research could be extended to include other factors such as Conscientiousness, Agreeableness, Openness to
Experience and Extra-version. Also, a similar study could be conducted to correlate the ego states with the HEXACO model of personality (Lee \& Ashton, 2012). Such research could enrich TA theory and position it in the light of contemporary theories of personality.

\section{Authors}

Vijay Gopal Sreenivasan can be reached at vijay10gopal@gmail.com. This research project was conducted as part of his MA (Psychology) course of the Indira Gandhi National Open University (IGNOU), New Delhi, India.

C. Suriyaprakash, Ph.D. is professor of Organisational Behaviour at Janson's School of Business, and a Teaching and Supervising Organisational Transactional Analyst from Coimbatore, India. He can be reached at suriya.sunshine@gmail.com

\section{References}

Akkoyun, Fusun. (2014). Research instruments: TArelated research instruments.

https://itaaworld.org/research-instruments accessed 20 July 2019

Berne, Eric. (1972). What do you say after you say hello? London: Corgi Books.

Berne, Eric. (1961). Transactional Analysis in psychotherapy - A systematic individual and social psychiatry. New York: Ballantine Books.

Ciucur, Daniel. (2013). The ego states and the Big Five personality factors. Procedia - Social and Behavioural Sciences, 78 (2013), pp. 581-585. doi:10.1016/j.sbspro.2013.04.355

Doelker, Richard E, Jr. \& Griffiths, John. (1984). Development of an instrument to measure ego state functions and its application to practice. Transactional Analysis Journal, 14(2), 149-152. doi: $10.1177 / 036215378401400210$

Dusay, John M. (1972). Egograms and the "Constancy Hypothesis". Transactional Analysis Journal, 2(3), 37-41. doi 10.1177/036215377200200313

Hathaway, S. R., \& McKinley, J. C. (1940). A multiphasic personality schedule (Minnesota): Construction of the schedule. Journal of Psychology, 10, 249-254.

Hathaway, S. R., \& McKinley J. C. (1942). Manual for the Minnesota Multiphasic Personality Inventory. Minneapolis: University of Minnesota Press.

Hay, Julie (1992) Transactional Analysis for Trainers Maidenhead: McGraw-Hill, (republished 1996) Watford: Sherwood Publishing 
Heyer, Robert N. (1979). Development of a questionnaire to measure ego states with some applications to social and comparative psychiatry. Transactional Analysis Journal, 9(1), 9-19. doi: 10.1177/036215377900900103

John, Oliver P., Naumann, Laura P., \& Soto, Christopher J. (2008). Paradigm shift to the integrative Big Five trait taxonomy - History, measurement and conceptual issues. In John, Oliver P., Robins, Richard W. \& Pervin, Lawrence A (Eds.), Handbook of personality: Theory and research (3rd ed., pp. 114-158). New York: The Guilford Press.

Kahler, T (1977) The Miniscript. In Barnes, G (ed) Transactional Analysis after Eric Berne New York: Harper's College Press Julie will add page nos

Kothari, C. R. \& Garg, Gaurav. (2014). Research methodology: Methods and Techniques (3rd ed.). New Delhi: New Age International (P) Ltd.

Lee, Kibeom. \& Ashton, Michael C. (2012). The H Factor of Personality - Why Some People are Manipulative, SelfEntitled, Materialistic, and Exploitive-And Why It Matters for Everyone. Ontario: Wilfrid Laurier University Press.

Loffredo, Donald A. \& Harrington, Rick. (2012). Letter to the editor, Transactional Analysis Journal, 42(1), 93-96. doi:10.1177/036215371204200112

Loffredo, Donald A., Harrington, Rick., Munoz, Martin K., \& Knowles, Laura R. (2004). The Ego State QuestionnaireRevised, Transactional Analysis Journal, 34(1), 90-95, doi:10.1177/036215370403400110

Loffredo, Donald A. (1998). The relationships among ego states, locus of control, and dogmatism. Transactional Analysis Journal, 28 (2), 171-173. doi: $10.1177 / 036215379802800211$

McCrae, Robert R. \& Costa, Paul T, Jr. (2008). The FiveFactor theory of personality. In John, Oliver P., Robins, Richard W. \& Pervin, Lawrence A (Eds.), Handbook of personality: Theory and research (3rd ed., pp. 159-181). New York: The Guilford Press.
Nettle, Daniel. (2007). Personality: What makes you the way you are. New York: Oxford University Press, Inc.

Nolen-Hoeksema, Susan., Fredrickson, Barbara L., Loftus, Geoffrey R., \& Lutz, Christel. (2014). Atkinson and Hilgard's introduction to psychology. (16th ed.). India: Cengage Learning EMEA.

Sava, A. F. (2008). Inventarul de personalitate DECAS Manual de utilizare. Timisoara: ArtPress

Schaeffer, Charles (1976) The development of a transactional analysis scale for the adjective check list. Journal of Psychology 94, 59-63

Schultz, Duane P. \& Schultz, Sydney E. (2013). Theories of personality. (10 $0^{\text {th }}$ ed.). India: Cengage Learning.

Stewart, lan. \& Joines, Vann. (1987). TA Today. Chapel Hill, USA: Lifespace Publishing.

Temple, Susannah. (2015). Celebrating Functional Fluency and its contribution to Transactional Analysis theory. Transactional Analysis Journal, 45(1), 10-22. doi:10.1177/0362153714568803

Thorne, Sylvia. \& Faro, Sharyn. (1980). The Ego State Scale: A measure of psychopathology. Transactional Analysis Journal, 10(1), 49-52. doi:10.1177/036215378001000115

Weiner, Irving B. \& Greene, Roger L. (2008). Handbook of personality assessment. Hoboken, New Jersey, USA: John Wiley \& Sons, Inc.

Williams, Kathryn B. \& Williams, John E. (1980). The assessment of Transactional Analysis ego states via the Adjective Checklist. Journal of Personality Assessment, 44(2), 120-129.

World Health Organization. (2019). Mental health in India. http://www.searo.who.int/india/topics/mental health/about mentalhealth/en/ accessed 20 July 2019 


\section{Appendix A: Significance testing of all correlations}

Note. All correlations are significant at 0.05 level using a two-tailed test.

\begin{tabular}{|c|c|c|c|c|c|}
\hline & \multicolumn{5}{|c|}{ Ego states } \\
\hline $\mathbf{r}$ & NP & CP & A & AC & FC \\
\hline $\mathbf{n}$ & -0.347 & 0.523 & -0.622 & 0.638 & 192 \\
\hline $\mathbf{d f}$ & 192 & 192 & 192 & 192 & 190 \\
\hline $\mathbf{p}$ & 190 & 190 & 190 & 190 & $1.005 \mathrm{E}-11$ \\
\hline
\end{tabular}

Table 5: Significance testing of $r$ : Ego states and Neuroticism (All respondents)

\begin{tabular}{|c|c|c|c|c|c|}
\hline & \multicolumn{5}{|c|}{ Ego states } \\
\hline & NP & CP & A & AC & FC \\
\hline $\mathbf{r}$ & -0.514 & 0.622 & -0.627 & 0.587 & -0.386 \\
\hline $\mathbf{n}$ & 71 & 71 & 71 & 71 & 71 \\
\hline $\mathbf{d f}$ & 69 & 69 & 69 & 69 & 69 \\
\hline
\end{tabular}

Table 6: Significance testing of $r$ : Ego states and Neuroticism (Males)

\begin{tabular}{|c|c|c|c|c|c|}
\hline & \multicolumn{5}{|c|}{ Ego states } \\
\hline & NP & CP & A & AC & FC \\
\hline $\mathbf{r}$ & -0.249 & 0.463 & -0.625 & 0.668 & -0.499 \\
\hline $\mathbf{n}$ & 120.00 & 120.00 & 120.00 & 120.00 & 120.00 \\
\hline $\mathbf{d f}$ & 118.00 & 118.00 & 118.00 & 118.00 & 118.00 \\
\hline $\mathbf{p}$ & 0.00612395 & $9.90081 \mathrm{E}-08$ & $2.27054 \mathrm{E}-14$ & $8.19506 \mathrm{E}-17$ & $6.66072 \mathrm{E}-09$ \\
\hline
\end{tabular}

Table 7: Significance testing of $r$ : Ego states and Neuroticism (Females) 


\begin{tabular}{|c|c|c|c|c|c|}
\hline & \multicolumn{5}{|c|}{ Ego states } \\
\hline & NP & CP & A & AC & FC \\
\hline $\mathbf{r}$ & -0.316 & 0.489 & -0.591 & 0.607 & -0.505 \\
\hline $\mathbf{n}$ & 119.00 & 119.00 & 119.00 & 119.00 & 119.00 \\
\hline $\mathbf{d f}$ & 117.00 & 117.00 & 117.00 & 117.00 & 117.00 \\
\hline $\mathbf{p}$ & 0.00047268 & $1.67867 \mathrm{E}-08$ & $1.42633 \mathrm{E}-12$ & $2.43283 \mathrm{E}-13$ & $4.79924 \mathrm{E}-09$ \\
\hline
\end{tabular}

Table 8: Significance testing of $r$ : Ego states and Neuroticism (25-40 yrs of age)

\begin{tabular}{|c|c|c|c|c|c|}
\hline & \multicolumn{5}{|c|}{ Ego states } \\
\hline $\mathbf{r}$ & NP & CP & A & AC & FC \\
\hline $\mathbf{n}$ & -0.388 & 0.519 & -0.672 & 0.735 & -0.382 \\
\hline $\mathbf{d f}$ & 43 & 43 & 43 & 43 & 43 \\
\hline $\mathbf{p}$ & 41 & 41 & 41 & 41 & 41 \\
\hline
\end{tabular}

Table 9: Significance testing of $r$ : Ego states and Neuroticism (41-56 yrs of age) 